\title{
O Arborescer das TIC na Educação: da raiz aos ramos mais recentes
}

\begin{abstract}
Jefferson Fagundes Ataíde
Nyuara Araújo da Silva Mesquita

Resumo

Este estudo de cunho teórico traz uma revisão bibliográfica no sentido de propor a descrição de parte da trajetória histórica das TIC na educação articulando com o entendimento de um conjunto de conhecimentos tecnológicos que levam a sociedade a se organizar em rede. Propõe-se também uma crítica aos dispositivos ideológicos que se conectam firmemente os direcionamentos passados e presentes da tecnologia na sociedade atual. $O$ estudo da localização histórica dos fatos referentes ao uso de TIC na educação permitiu inferir que o progresso atual segue em direção à introdução maciça de tecnologias no ambiente escolar em reflexo à abrupta expansão do mercado tecnológico em consonância aos pressupostos ideológicos fundamentalmente aderidos ao capital. Nesse sentido, fortalece-se a preocupação das ciências sociais em justaposição aos estudos educacionais no sentido de promover uma apropriação mais crítica das tecnologias em uma perspectiva não exclusiva ao contexto escolar.
\end{abstract}

Palavras-chave: arborescer das TIC, educação, ideologia e tecnologia.

\begin{abstract}
The arborescence of ICT in education: from the root to the branches newer

This work provides a theoretical review of the literature to propose a description of the historical trajectory of ICT in education articulating with the understanding of a set of technology skills that lead society to organize network. It also proposes a critique of ideological devices that connect tightly the directions past and present technology in today's society. The study of the location of the historical facts relating to the use of ICT in education also has shown that the current progress goes toward the massive introduction of technology in the school environment reflecting the abrupt expansion of the technology market in line with ideological presuppositions fundamentally adhered to the capital. In this sense, strengthens the concern of the social sciences in educational studies in juxtaposition to promote a more critical appropriation of technologies from a perspective not exclusive to the school.
\end{abstract}

Keywords: arborescence of ICT, education, ideology and technology.

\section{Introdução}

O presente estudo de caráter teórico e apoiado em na revisão da literatura disponível, traz um recorte dos principais eventos que marcaram o caminho histórico das Tecnologias da Informação e Comunicação (TIC) no mundo e posteriormente no Brasil. Para isso, estabelece-se semanticamente uma paridade com o signo árvore na estruturação e disposição das ideias. Antes 
de partir para a abordagem do contexto tecnológico historicamente localizado, propõe-se um breve olhar no conceito de "sociedade em rede". Em seguida, são apresentados três galhos ou ramificações que representam parte da relação histórica da educação com a tecnologia com ênfase significativa para o contexto brasileiro. A posteriori, destaca-se a discussão das raízes ideológicas da tecnologia, apresentando argumentos que incitam uma compreensão mais crítica do percurso histórico das tecnologias sob influência dos mecanismos ideológicos.

Etimologicamente a palavra tecnologia possui origem grega ( $\tau \varepsilon \chi \vee \eta \lambda o \gamma\llcorner\alpha)$ sendo tekhné ( $\varepsilon ₹ \chi \vee \eta)$ significando arte, técnica ou ofício e logos ( $\lambda \circ \gamma(\alpha)$ como o estudo e o discurso aplicado a uma determinada técnica. A origem da palavra traz, portanto, um entendimento e um significado para além de concepções mercadológicas bem como daquelas que concebem as tecnologias apenas como um conjunto de equipamentos eletrônicos. O fato de também significar uma manifestação da arte do saber fazer, remete aos tempos gregos cujos dominadores das técnicas eram os artesãos, senhores da sua própria arte (KNELLER, 1978). O termo tecnologia ganhou mais força a partir da Revolução Industrial no final do século XVIII e a partir de então, passou a ser interpretado de diferentes maneiras e por distintas áreas do conhecimento e deste modo, já não existe uma acepção aplicável a todos os contextos sociais (GAMA, 1987). A partir daqui, o emprego da palavra técnica estará semanticamente próximo de tecnologia na tentativa de explorar um sentido mais amplo do termo e também por questões estéticas do texto.

Deve-se entender que desde o surgimento das tecnologias ao dimensionamento e diversificação atual de todos os tipos de tecnologias, se passou muito tempo legitimando a necessidade de uma abordagem valorizadora do caráter histórico do conhecimento humano. Técnicas consideradas novas atualmente surgem com significativa rapidez devido à soma e articulação dos inúmeros conhecimentos humanos de áreas diversas. Cada época e contexto exprime um conjunto de conhecimentos da técnica considerados avançados e que, com o passar do tempo, reverberam na elaboração de novos conhecimentos funcionando assim, como um alicerce à elaboração de novas tecnologias.

A organização humana em uma sociedade complexa é, em grande parte, resultado da elaboração de técnicas de se expressar, de se relacionar e de representar o mundo a sua volta. Nesse caso, Kenski (2003) e Marcondes Filho (1994) apoiam a ideia de que, desde contextos préhistóricos, o homem vem fazendo uso das tecnologias e a partir daí todas as épocas podem ser representadas seja pela elaboração ou pelo apogeu de algum conhecimento da técnica. Um dos primeiros passos que futuramente possibilitariam a existência do desenvolvimento tecnológico contemporâneo foi o registro via símbolos icnográficos mostrando hábitos de vida, de caça, de rituais e danças do homem pré-histórico.

Os caminhos trilhados pela educação no mundo sempre foram fortemente influenciados pelas transformações socioeconômicas das sociedades. Deste modo, nota-se que o crescente uso das tecnologias trouxe, bem ou mal, novas possibilidades de interação, comunicação e 
aprendizagem. Um dos pontos fundamentais para a construção do conhecimento humano é a relação deste com seu semelhante, à medida que seu carácter distintivo é historicamente localizado e construído.

Horizontalizando o olhar, nota-se que as relações entre os indivíduos sofreram alterações no que diz respeito à fidedignidade e à intencionalidade comunicativa dessas relações. Toma-se como fidedignidade a real mensagem que se deseja passar de uma pessoa a outra e, intencionalidade comunicativa como um ato consciente do propósito de cada ação de se comunicar com o outro. Ou seja, essas mesmas relações eram desenvolvidas diretamente via indivíduo-indivíduo sem a presença de um "terceiro", que nesse caso seria qualquer aparato tecnológico como, por exemplo, o computador e a internet (DONNAMARIA e TERZIS, 2012). Sendo assim, pode-se dizer que ao mesmo tempo em que a tecnologia aumenta a velocidade e variedade dos meios de se comunicar, perde-se em fidedignidade e altera-se a intencionalidade comunicativa na construção e desenvolvimento das relações humanas.

Como exemplo à argumentação anterior, tem-se o caso das "redes sociais digitais" podendo ser compreendidas como uma reunião de pessoas, que não necessariamente se conhecem, mantendo interações múltiplas e a distância apoiadas centralmente pela internet. Nesse sentido, as relações funcionam num circuito indivíduo-tecnologia-indivíduo, sendo assistidas obrigatoriamente pelas ferramentas disponibilizadas pelos sites e pela internet de forma geral.

Não é a intenção deste texto centralizar a posição da tecnologia, colocando-a como elemento determinante da vida social e muito menos de marginalizá-la, ignorando seu papel como uma importante via de interconectividade individual e coletiva. Castells (2005) traz argumentos que auxiliam no entendimento de que a sociedade, tal como a conhecemos atualmente, não aponta a tecnologia de forma geral como único direcionamento, mas é impensável concebê-la apartada da histórica relação para com a técnica.

O que se sabe é que a construção da identidade social é atualmente muito influenciada tecnologicamente. Os mass media divulgam com relativa intensidade e frequência que o avanço tecnológico trouxe apenas benefícios à vida humana, opinião compartilhada por alguns autores como Domingues (1986) ao sugerir que o sistema técnico atual tem como fundamentos elementares a automatização e a micro eletrônica - incluindo aí as tecnologias da comunicação e da informação - que rompendo com o sistema técnico anterior direcionam a um emergente sistema técnico com maior rentabilidade, flexibilidade, qualidade e produtividade, com importantes transformações no nível socioeconômico.

Compreende-se que o equívoco nesta argumentação consiste em associar a rentabilidade, a flexibilidade e uma maior produtividade com a qualidade, essencialmente àquela pretendida para transformações sociais e econômicas. É nesse cenário que nasce a necessidade alienada do 
jovem em construir relações interpessoais e expor sua identidade social unicamente por meio das tecnologias sem que haja uma apreensão mais crítica das mesmas (NOGUEIRA, 1998). Atrás das cortinas estão interesses maiores que buscam, dentre outras coisas, manter em estágio cada vez mais crescente o consumo de tecnologias. Necessidades são assim criadas e substituídas em um curto intervalo de tempo configurando o que se pode nomear de "novidades tecnológicas obsolescentes".

No caminho histórico e biológico da evolução humana, o desenvolvimento complexo do cérebro, com sua gigantesca quantidade de conexões sinápticas, deu condições ao indivíduo de ter uma incrível capacidade de negligenciar alguns elementos da realidade imaginando um novo mundo, sujeito a novas regras e novos valores. Assume-se que cada ser humano em seu caráter subjetivo é fruto de influências ambientais diversas - incluindo influências sociais, biológicas e tecnológicas - e isso faz com que exista uma singularidade nas referidas conexões sinápticas e, consequentemente, no potencial de abstração e também de aprendizagem.

Nesse sentido, alguns autores defendem que a virtualidade sempre esteve presente no imaginário humano. $\mathrm{O}$ que torna a imaginação diferenciada contemporaneamente é que graças à variada disponibilidade de TIC, novas realidades podem ser construídas, como, por exemplo, a realidade das comunidades virtuais (DUART e SANGRÀ, 2000). De modo geral, os ambientes virtuais exibem condições para que os indivíduos possam se comunicar - incorporando aspectos educacionais, culturais e profissionais - de maneira assincrônica, não havendo a necessidade de estar simultaneamente no mesmo tempo e espaço. Destacando um pouco mais a questão da virtualidade, Lévy (1999, p. 47) diz o seguinte:

"[...] A palavra 'virtual' pode ser entendida em ao menos três sentidos: o primeiro, técnico, ligado à informática, um segundo corrente e um terceiro filosófico. O fascínio suscitado pela "realidade virtual" decorre em boa parte da confusão entre esses três sentidos. Na acepção filosófica, é virtual aquilo que existe apenas em potência e não em ato, o campo de forças e de problemas que tende a resolver-se em uma atualização. $O$ virtual encontra-se antes da concretização efetiva ou formal (a árvore está virtualmente presente no grão). No sentido filosófico, o virtual é obviamente uma dimensão muito importante da realidade. Mas no uso corrente, a palavra virtual é muitas vezes empregada para significar a irrealidade enquanto a 'realidade' pressupõe uma efetivação material, uma presença tangível".

Ainda segundo Lévy (1993), o conhecimento elaborado pelas sociedades pode ser apresentado a partir de três categorias distintas: escrita, oral e digital. Nesse prisma, Kenski (1998) argumenta que apesar de tais categorias possuírem origem em épocas diferentes, elas coexistem atualmente. Para além da coexistência, há uma relação de interdependência na qual 
uma dá suporte à outra, sendo que as categorias escrita e oral se constituem como condições sine qua non à existência da categoria digital. Fortalecendo o exposto, Kenski (1998, p. 61) afirma que:

\begin{abstract}
"A forma escrita de apreensão do conhecimento é a que prevalece em nossas culturas letradas, mas a linguagem oral ainda é a que predomina em todas as formas comunicativas vivenciais. Em meio a elas, e utilizando-se de ambas, o estilo digital de apreensão de conhecimentos é ainda incipiente, mas sua proliferação é veloz. O estilo digital engendra, obrigatoriamente, não apenas o uso de novos equipamentos para a produção e apreensão de conhecimentos, mas também novos comportamentos de aprendizagem, novas racionalidades, novos estímulos perceptivos".
\end{abstract}

Ao aceitar circunstancialmente a formação da identidade humana como fruto de influências diversas, não se pode desconsiderar o contexto contemporâneo no desenvolvimento de identidades neonatas. Ou seja, as gerações mais novas, nascem e crescem em um bombardeio de informações que de uma maneira ou de outra direcionam o indivíduo a um determinado posicionamento diante da informação, seja ele crítico ou não, a depender, também, da qualidade do processo educativo.

O palco de debates envolvendo tecnologias na educação conta com um suporte teórico rico e bem estruturado. Todavia, existem algumas lacunas a serem preenchidas no que diz respeito à distância entre tantos estudos teóricos e sua aplicabilidade. Isso não significa que tais construções acadêmicas não possuam um nível significativo de representatividade do contexto educacional, mas que existem entraves de cunho político e econômico que devem ser desvelados e, por fim, dirimidos (BUARQUE, 1997).

As tecnologias não devem ser esquecidas ou incluídas de maneira arbitrária na construção e desenvolvimento dos processos pedagógicos, uma vez reconhecido o papel da técnica na gênese e divulgação de saberes. Perrenoud (2000) propõe que uma das competências atualmente necessárias para ensinar é a utilização de novas tecnologias. De modo mais específico o autor defende a utilização de editores de texto, a exploração do potencial didático dos aplicativos, a comunicação extraclasse intermediada pela telemática e o uso de ferramentas multimidiáticas no ensino. Mesmo assumindo que as práticas pedagógicas estão se tornando cada vez mais dependentes das tecnologias audiovisuais e informatizadas (PERRENOUD, 2000), estas não podem ocupar uma posição primária em caráter de relevância ao processo de ensino. Nesse sentido, tendo como exemplo o caso da utilização de softwares como apoio aos processos de ensino, assume-se a partir de Perrenoud (2000, p. 143) que: 
"Os softwares de assistência ao trabalho de criação, de pesquisa, de processamento de dados, de comunicação e de decisão são feitos para facilitar tarefas precisas e para melhorar o rendimento e a coerência do trabalho humano. Seu domínio obriga a planejar, decidir, encadear operações, orquestrar e reunir recursos. Tudo isso colabora para a formação de competências essenciais, para cuja construção o instrumento é secundário em relação às operações mentais e as qualidades mobilizadas: rigor, memória, antecipação, regulação".

A preocupação com o uso de tecnologias como apoio pedagógico no processo de ensino e aprendizagem se iniciou pouco antes da década de 1970, sobretudo em Portugal, França e Estados Unidos (ALMEIDA, 2008). Um pouco antes do nascimento de tal preocupação, emerge um novo paradigma da técnica - relação entre os novos eventos científico-tecnológicos e a organização da sociedade em geral - que começa a tomar forma a partir dos anos 1960 repercutindo desigualmente por todo o mundo (CASTELLS, 2005).

Esse movimento foi, em parte, influenciado pelo consumo e pela produção do chamado personal computer pela International Business Machines (IBM) em 1981 (CASTELLS, 2000). O computador pessoal (PC) foi produzido para atender aos crescentes anseios de camadas mais populares da sociedade sendo, por exemplo, incorporado ao lazer, à facilitação dos estudos e tarefas administrativas em empresas dos mais variados tamanhos. O contexto das alíneas anteriores ganhou condições de gênese e crescimento a partir de 1951, ano da primeira tentativa de construção de um computador que resultou numa máquina chamada UNIVAC 1 (ALTOÉ e SILVA, 2005).

A popularização do $\mathrm{PC}$, bem como da difusão da rede mundial de computadores, deram condições ao nascimento de basicamente dois novos contextos: o do amplo armazenamento e disponibilização de informações e o das complexas relações entre sujeitos, culturas e conhecimentos sob mediação tecnológica. Imbricada a ambos os contextos, está a relação dos sujeitos com a tecnologia, construída historicamente sob o crivo da ideologia do capital (WOOD, 2003).

Antes mesmo de se tornar presente no cenário pedagógico, as TIC, de forma geral, foram introduzidas no contexto norte americano, europeu e brasileiro a princípio como ferramenta de apoio técnico-administrativo em secretarias, coordenadorias, gabinetes de gestores e institutos das universidades. De forma semelhante, as escolas se tornaram, posteriormente, o foco das atenções para que pudessem ser equipadas fundamentalmente com computadores e outras ferramentas de suporte à rede de internet. 


\title{
o Conceito de Sociedade em Rede
}

O papel de interconexão que a técnica exerce para com sujeitos, culturas e conhecimentos faz surgir o que Castells (2005) denomina de "sociedade em rede". Esta, para o autor, se configura como uma estrutura social fundamentalmente apoiada em redes assistidas por tecnologias de informação e comunicação com a presença marcante da microelectrônica e das redes digitais de computadores que criam, processam e transmitem informações largamente acumuladas e disponibilizadas. A noção de ênfase não exclusiva no computador e na rede mundial de computadores para concretização de uma sociedade em rede é defendida por Castells (2005, p. 337) ao dizer que:

\begin{abstract}
"Devemos considerar que o contexto tecnológico da sociedade em rede é estabelecido não apenas por microprocessadores e pela Internet, mas por uma onda emergente de diversas novas tecnologias que encontram as suas utilizações por relação entre elas".
\end{abstract}

Salienta-se que a questão da sociedade em rede não se configura como foco de análise da presente pesquisa, no entanto, reconhece-se que alguns aspectos inerentes ao conceito são importantes para dar corpo às discussões aqui apresentadas. O entendimento do conceito de sociedade em rede implica numa exploração de vários outros contextos para além do contexto educacional. Deste modo, é preciso investigar, não isoladamente, temáticas que dialogam entre si a partir de uma rede complexa de conhecimentos envolvendo áreas como economia, sociologia, política e educação.

Na perspectiva de Castells (2005), a sociedade em rede é algo que se desenvolveu concomitantemente ao rumo tomado pelo conjunto de sociedades que fundamentaram sua estruturação a partir do conhecimento científico. Portanto, é um sistema de organização em redes que se tornou necessário à fundação e desenvolvimento de um macro-sistema político, social e econômico. Toda a sociedade está incluída nessa rede ainda que nem tudo e nem todos os indivíduos estejam contemplados. A sociedade em rede é estruturalmente flexível e em detrimento do seu estreito relacionamento com o sistema econômico dominante, também admite a exclusão em suas mais variadas formas. Nesse sentido, Castells (2005, p. 18), aponta que a sociedade em rede "exclui a maior parte da humanidade, embora toda a humanidade seja afectada pela sua lógica, e pelas relações de poder que interagem nas redes globais da organização social".

Do ponto de vista político, a sociedade em rede exprime algumas circunstâncias condicionais para que possa exercer uma maior abrangência. Ou seja, partindo do princípio que a organização social em rede também traz benefícios à vida humana, é necessário um comprometimento do setor público no sentido de ampliar o número de indivíduos beneficiados. A 
esfera de gestão pública é atualmente imprescindível para desenvolver e moldar a sociedade em rede. Enaltecendo o exposto, a partir de Castells (2005, p. 27), temos que:

"A moldagem e a condução desta sociedade está, como esteve sempre no caso das outras, nas mãos do sector público, apesar do discurso ideológico que pretende esconder esta realidade. Contudo, o sector público é a esfera da sociedade em que as novas tecnologias de comunicação estão menos difundidas e os obstáculos à inovação e ao funcionamento em rede são mais pronunciados".

O prisma econômico é outro componente que se enlaça aos demais contextos da sociedade em rede. Ao analisar um panorama histórico do desenvolvimento da economia a partir das contribuições de Castells (2005), nota-se que a estruturação social em rede também surge a partir do processo de transição da sociedade rural, passando pela sociedade industrial e culminando numa sociedade pós-industrial marcadamente caracterizada pela disponibilização em massa da informação em um nível global.

É preciso ter cuidado ao se tratar de alguns aspectos globalmente abrangentes, sobretudo àqueles que se encaixam no conceito de globalização, compreendido aqui como a soma e articulação de processos de criação e disponibilização facilitada de recursos tecnológicos aliados a novas estratégias de informação e comunicação, de mercado financeiro e por fim de organização social. Tudo isso culminando em uma diminuição das fronteiras naturalmente criadas pela identidade de cada povo e cultura. Dale (2004, p. 424) dá condições para um entendimento semelhante ao afirmar que:

"A 'globalização' é frequentemente considerada como representando um inelutável progresso no sentido da homogeneidade cultural, como um conjunto de forças que estão a tornar os estados-nação obsoletos e que pode resultar em algo parecido com uma política mundial, e como reflexo do crescimento irresistível da tecnologia da informação".

Castells (2005) assume a equivalência conceitual entre globalização e sociedade em rede mesmo que este último seja mais analítico e menos descritivo. O cuidado citado no parágrafo anterior, também sob o crivo dos argumentos de Castells (2005), refere-se à adoção de uma postura crítica que deve presidir a aceitação de um determinado conceito e, no caso da globalização, deve-se reconhecer que ao longo da história humana alguns eventos catastróficos como o Holocausto Nazista e a ditadura de Stalin, a criação e o uso da bomba atômica, dentre muitos outros não menos importantes, serviram de provas do potencial destrutivo da Era Industrial a partir de um mal uso de conhecimentos científicos. Cita-se ainda, o caso da coexistência das maravilhas da revolução tecnológica com processo autodestrutivo de estímulo 
ao desequilíbrio do efeito estufa e a criação de condições de ressurgimento e persistência de muitas doenças principalmente em países apartados de tais maravilhas da técnica.

O conceito de sociedade em rede permite, dentre outras coisas, entender a pertinência de trazer um pouco de alguns contextos externos à educação brasileira, pois, compreende-se, em concordância ao trabalho de Almeida (2008), que a educação no Brasil exprime diversas influências oriundas de políticas educativas europeias e norte-americanas que fundamentam uma proximidade histórica entre os modelos educacionais.

Retornando à proposição inicial deste texto, o estabelecimento de uma relação metafórica entre o signo árvore e a estruturação do contexto histórico das tecnologias no processo de articulação com o campo educacional, dispõe-se a seguir alguns dos galhos representativos da árvore chamada realidade social. Cada galho sinaliza alguns dos principais eventos históricos relacionados ao processo de aproximação e desenvolvimento das TIC no cenário educacional peculiar a cada contexto. Extraindo um pouco mais da potencialidade explicativa e estética de uma metáfora para justificar a apresentação dos galhos supracitados, pensa-se que uma ave que sobrevoa uma árvore qualquer tem desta uma visão panorâmica e privilegiada, que não seria possível se essa mesma ave resolvesse pousar e observar unicamente a partir de um de seus galhos. Deste modo, é necessário contemplar várias realidades sociais que a princípio se diferenciam em tudo umas das outras que, sob um ponto de vista mais crítico, pronunciam semelhanças fundamentais à apreensão de uma determinada problemática social.

\section{Primeiro Galho: o contexto dos EUA}

A história da aplicação de tecnologias no campo educativo norte-americano se iniciou a partir da década de 1940 com o objetivo inicial de formar especialistas militares durante a Segunda Guerra Mundial. Para isso, foram criados cursos que contavam com o apoio de ferramentas audiovisuais. A Universidade de Indiana foi umas das pioneiras no contexto estadunidense a incorporar, em 1946, a temática tecnologias nos estudos sobre currículo escolar (ATOÉ e SILVA, 2005).

Algumas das primeiras intervenções no sentido de informatização das escolas aconteceram nos Estados Unidos da América, nos anos finais da década de 1950, por meio do "National Science Foundation and Department of Education". Ainda assim, a introdução de computadores nas escolas americanas tornou-se mais efetiva a partir de meados da década de 1970 e início de 1980, com o uso de computadores em pequeno quantitativo de escolas (ALMEIDA, 2008).

As propostas norte-americanas para o uso do computador nas escolas se baseavam em estudos e desenvolvimento de software do tipo CAI (Computer Aided Instruction). Os softwares tipo CAl estavam alicerçados em teorias comportamentalistas nas quais o computador munido de 
determinados softwares cumpria o papel de instrutor com atividades programadas e com passos guiados (ALMEIDA, 2008).

Do ano de 1970 em diante, cresce o número de pesquisadores dedicados ao desenvolvimento de softwares, especialmente do tipo CAl, fundamentados em teorias do comportamento humano. Com isso, o uso do computador é direcionado a uma perspectiva educacional instrucionista, na qual o usuário é guiado por instruções previamente fixadas nos softwares. Grandes empresas como a IBM transformaram a ideia desses sistemas eletrônicos em produtos para os mais variados tipos de consumidores (ALMEIDA, 2008).

Conforme mencionado por Pretto (1996), o movimento de abeiramento entre as grandes indústrias da informática, do entretenimento, da informação, do mundo eletrônico em geral e da cultura ficou impresso nas últimas décadas do século XX. Este processo apresentou basicamente três consequências: o crescimento acelerado dos sistemas de comunicação em todo o mundo, o nascimento de uma nova perspectiva de mundo em praticamente todas as expressões do conhecimento e a introdução de uma nova razão mais global e mais complexa.

A sofisticação dos processos de interatividade entre os softwares e os usuários acontece a partir da incorporação de recursos hipermidiáticos aliados a um sistema de tratamento avançado das informações (ALMEIDA, 2008). Permite-se então, a classificação distributiva dos conteúdos em módulos específicos cada um com um conjunto de instruções que podem ou não serem peculiares a cada módulo, conteúdo, ou público alvo. Tal sofisticação dependeu essencialmente do desenvolvedor do software no fornecimento de ferramentas específicas do programa de computador, bem como do corpo gestor que adequa uma determinada plataforma eletrônica aos objetivos acordados para a execução de uma atividade em particular.

Dois tipos de enfoques equivocadamente entendidos como conflitantes, na visão de Valente e Almeida (1997), são evidenciados em consequência da realização de alguns eventos como a conferência Ten-Year Forecast for Computer and Communication: Implications for Education em 1975. O primeiro dos enfoques diz respeito às circunstâncias de mercado que, por volta da década de 1970, impulsionavam o desenvolvimento e a distribuição de software tipo CAl. O segundo enfoque está relacionado ao crescente entusiasmo em utilizar o computador como uma das principais ferramentas na promoção de transformações qualitativas na educação (VALENTE e ALMEIDA, 1997).

Ambos os enfoques ganharam força na mesma época e respeitando as peculiaridades de cada um nos seus devidos contextos, é visível a participação mútua em um cenário de valorização da tecnologia, sobretudo daquelas intimamente relacionadas aos computadores. Portanto, percebe-se que apesar de ter início nos anos de 1951, a expansão das tecnologias no contexto social norte-americano como um todo, especialmente o educacional, ocorreu a partir dos anos de 1970, época do tecnicismo educacional. 
Em 1984, a UNESCO propõe um novo entendimento para o contexto mídia-educação na tentativa de contemplar um pouco mais a complexidade do fenômeno de apropriação da técnica pelo campo educacional (BÉVORT e BELLONI, 2009). Sendo assim, a UNESCO (1984) define a relação mídia-educação como:

"Todas as maneiras de estudar, aprender e ensinar em todos os níveis (...) e em todas as circunstâncias, a história, a criação, a utilização e a avaliação das mídias enquanto artes práticas e técnicas, bem como o lugar que elas ocupam na sociedade, seu impacto social, as implicações da comunicação mediatizada, a participação, a modificação do modo de percepção que elas engendram, o papel do trabalho criativo e o acesso às mídias".

Acontece nos EUA por volta do ano de 1980, uma queda no movimento de defesa da "media literacy" que pode ser traduzido como "alfabetização para a mídia". A media literacy compreende o desenvolvimento de competências e habilidades para o uso responsável das mídias rumo à alfabetização na midialidade ${ }^{11}$ criando condições de uma interpretação bem fundamentada das relações sociais vivenciadas e assinaladas pelos valores característicos das mídias. Almeida (2008) destaca que a media literacy voltou a ganhar força a partir de 1990 provavelmente por influências de resultados de algumas investigações científicas relativas ao multiculturalismo e ao construtivismo. Nessa época, uma reforma educacional norte-americana também trouxe condições de incentivo à autonomia docente e à incorporação de elementos pedagógicos de apoio ao caráter inovador e criativo do professor.

A presença das TIC como ferramentas de apoio pedagógico e como objeto de estudo incorporado ao currículo escolar se consolida a partir do ano de 2000 via orientações do governo americano em consonância aos estudos desenvolvidos pelas universidades. O processo de integralização crítica da temática tecnologias nos espaços escolares ainda se concretiza atualmente nos EUA, podendo também ser identificado no contexto europeu e brasileiro (ALMEIDA, 2008).

1 A midialidade segundo Bauer (2011, p. 16) contempla a "qualidade da prática social (comunicacional) em uma sociedade instituída pela mídia e, assim, tornou-se o paradigma de comunicação em uma sociedade que se constitui e se organiza no modelo da mídia: a sociedade crescentemente toma conta e avalia a si mesma através de indicadores tipicamente midiáticos e valores relacionados a ela - valores-notícia, atenção pública, visibilidade pública, disponibilidade, elemento de prazer, caráter conversacional, conectividade comunicativa, prática comunicativa, dentre outros". 


\section{Segundo Galho: o contexto europeu}

Os caminhos percorridos pelas iniciativas do Reino Unido para introduzir as tecnologias nos espaços escolares foram distintos. As ações apontaram para uma tendência com ênfase na Aprendizagem ao Longo da Vida (Life Long Learning), implementando em 1977 o Programa de Desenvolvimento Nacional de Aprendizagem Assistida por Computador (National Development Programme For Computer Assisted Learning) - primeiro projeto que levaria computadores às escolas. Mais tarde, em 1989, demonstrando uma preocupação maior com a questão curricular, foi elaborado o Projeto "National Curriculum", no qual as diferentes disciplinas deveriam se estruturar também a partir do uso dos computadores (ALMEIDA, 2008).

Um dos primeiros documentos a sinalizar uma preocupação com a inserção de recursos tecnológico-midiáticos na educação foi a Declaração de Grunwald, de 1982. Convidados pela UNESCO, educadores, investigadores e comunicadores vindos de 19 países se reuniram no Simpósio Internacional sobre Educação para os Media na cidade de Grunwald na Alemanha (BÉVORT \& BELLONI, 2009). A posteriori, as iniciativas mundiais de aproximação das TIC para com a educação expressaram sensível ligação ao documento em questão. A declaração parte do princípio da ascendência participativa das mídias em contextos múltiplos da sociedade e reconhece a necessidade de uma compreensão e inserção mais crítica das tecnologias no campo educacional. Nessa direção, a UNESCO $(1982$, p. 2) expressa que:

"A educação para os media tornar-se-á mais eficaz quando pais, professores, profissionais dos media e decisores, todos eles, reconhecerem que têm um papel a desempenhar no desenvolvimento de uma maior consciência crítica entre ouvintes, espetadores e leitores. Uma maior integração dos sistemas educativos e de comunicação seria sem dúvida um passo importante no sentido de uma educação mais eficaz".

Na França, o processo de informatização das escolas começou na década de 70 e ganhou força a partir de 1980. O foco das ações de incorporação do computador nas escolas francesas era a produção de hardwares, softwares e a preparação dos docentes para atuarem em um contexto emergente (ALMEIDA, 2008). A iniciativa francesa para com as TIC nas instituições escolares desencadeou uma série de argumentos que propunham uma crítica ao simples ato de trazer aparatos tecnológicos à escola. Nesse sentido, Dieuzeide (1980, p. 52) destaca a necessidade de um olhar diferenciado sobre inovações vindas de um contexto exterior ou mesmo submetidas sob uma influência puramente hierárquica, pois estas podem não trazer bons frutos.

Em Portugal a proposta de introdução do computador na rede pública de ensino foi guiada inicialmente pelo Projeto Minerva (Meios Informáticos na Educação: Racionalizar, 
Valorizar, Atualizar) lançado em 1985 e encerrado em 1994. Esse projeto tinha como objetivo incluir o uso das tecnologias da informação e comunicação na educação básica em Portugal. Uma vez encerrado, o Projeto Minerva foi substituído em 1996 pelo Programa de Tecnologias da Informação e da Comunicação na Educação (Programa Nónio, século XXI). Ambas as iniciativas governamentais apresentaram suas fragilidades, no entanto, cumpriram de forma significativa a proposta de introdução das TIC no ambiente escolar (PORTUGAL, 2003).

Foram criados Centros de Competência localizados em instituições de ensino superior portuguesas e outras organizações educacionais encarregadas de fornecer apoio, orientação e acompanhamento aos projetos elaborados localmente pelas escolas. Cada projeto era avaliado quanto às dimensões técnica, apropriação teórica e prática e com relação à adequação do projeto frente aos objetivos propostos pelo Ministério da Educação - ME (ALMEIDA, 2008).

Castells (2005) evidencia que nem todas as sociedades estão estruturalmente dispostas em rede. Muitos países se encaixam no que o autor denomina de sociedade em transição para um modelo informacional, tendo Portugal como um dos exemplos europeus. Castells (2005, p. 33) afirma que:

"A análise de Portugal permite-nos perceber que se trata de um país que através das suas múltiplas redes de pertença (que vão da inserção na União Europeia à manutenção das boas relações, na óptica da defesa, com os EUA, ao estabelecer de redes de parceria com o Brasil, com as ex-colónias africanas e asiáticas e as regiões dotadas de autonomia na vizinha Espanha) procura adaptar-se às condições de mudança da economia global. E esse é um padrão comum a todas as sociedades em transição".

Sendo assim, compondo parte da rede de eventos históricos que reverberaram na existência e no desenvolvimento da realidade das TIC na educação brasileira, considera-se pertinente a apresentação de alguns aspectos inerentes ao contexto brasileiro e que não deixa de exprimir suas proximidades com as realidades norte-americanas e europeias.

\section{Terceiro Galho: o contexto brasileiro}

No Brasil começa-se a introduzir a informática na educação a partir da segunda metade da década de 1970 e mais intensamente no início dos anos 1980. Isso ocorreu principalmente no âmbito do ensino superior com universidades incorporando progressivamente as tecnologias nos seus espaços formativos. O objetivo era formar profissionais em sintonia aos novos padrões de mercado construídos pela sociedade emergente.

Em 1981 e 1982 aconteceram as duas primeiras edições do Seminário Nacional de Informática em Educação. Estes seminários foram promovidos em parceria com o Ministério da 
Educação (MEC) que, em resumo, culminaram na estruturação da Comissão Especial de Informática na Educação vinculada à Secretaria Especial de Informática - SEI (ALMEIDA, 2008) abrindo, em tese, mais espaço para uma aproximação progressiva entre a informática e a educação.

Em 1984, o MEC, mediante colaboração da Universidade Estadual de Campinas (UNICAMP), elaborou e instituiu o EDUCOM (Educação com Computador) que se tornou o primeiro programa a orientar professores e demais profissionais da educação para alcançar a informatização das escolas brasileira. O EDUCOM foi construído a partir de outro projeto da UNICAMP, o “Projeto Logo" vinculado ao Núcleo de Informática Aplicada à Educação (NIED).

O EDUCOM tinha o objetivo de consolidar uma filosofia diferenciada ao uso do computador nos espaços educativos, nas áreas de Matemática, Física, Química, Biologia, e Letras (Língua Portuguesa). O projeto assume uma postura filosófica na qual o computador é essencialmente uma ferramenta de apoio aos processos de ensino e aprendizagem, postura acordante com as construções teóricas para o entendimento da relação computador-escola. Por meio desta perspectiva, a aprendizagem assistida adequadamente pelo computador é guiada pela exploração e pela descoberta, dando mais autonomia ao aluno para um fazer ativo (UNICAMP, 2013).

A primeira LDB, Lei no 4024, de 20 de dezembro de 1961, apresentou algumas fragilidades sendo que uma delas se refere à questão das tecnologias na educação. A LDB/1961 cita a perspectiva da técnica no contexto educativo uma única vez, ao descrever os fins da educação, preconizando a necessidade do "preparo do indivíduo e da sociedade para o domínio dos recursos cientificos e tecnológicos que Ihes permitam utilizar as possibilidades e vencer as dificuldades do meio" (BRASIL, 1961). O destaque cabe à televisão que vinha ganhando cada vez mais influência nos debates sobre tecnologias aplicadas à educação. Nessa mesma década de 1960, tem-se o marco inicial do período tecnicista da educação brasileira.

A mesma fragilidade encontrada na primeira versão se repete na segunda versão, a LDB de 1971. A questão das tecnologias é mencionada unicamente no Art. 43 que se refere à destinação de recursos públicos à educação no sentido de manter o desenvolvimento do ensino oficial e assegurar também o desenvolvimento da ciência e da tecnologia. Infere-se que a problemática envolvendo a incorporação tecnológica na esfera educacional sequer é citada.

A versão atual da LDB, Lei no 9394 de 20 de dezembro de 1996, traz diversas modificações relevantes ao contexto educacional, mas, não se observa uma preocupação com o uso e compreensão mais crítica das tecnologias de modo geral. O Art. 32, inciso II, faz referência ao ensino fundamental, definindo a formação básica do cidadão como objetivo desse nível de ensino. Para isso, é necessário "a compreensão do ambiente natural e social, do sistema político, da tecnologia, das artes e dos valores em que se fundamenta a sociedade" (BRASIL, 1996). Como 
uma das finalidades para o ensino médio, o inciso IV do Art. 35 aponta na direção da "compreensão dos fundamentos científico-tecnológicos dos processos produtivos, relacionando a teoria com a prática, no ensino de cada disciplina" (BRASIL, 1996).

Para o ensino superior, no Art. 43, inciso III, da LDB/1996, a importância da técnica está no incentivo à investigação científica com o objetivo de desenvolver a ciência e suas tecnologias. Apesar de ter sofrido alterações de caráter essencial, a abordagem das tecnologias no âmbito educacional não está contemplada. A formação inicial ganha destaque na LDB/1996 a partir de orientações elaboradas com mais critério, todavia, não engendra o potencial formativo e a inserção crítica das TIC na escola.

Em 1997, a recém-inaugurada Secretaria de Educação a Distância (SEED) em articulação com o Ministério da Educação (MEC), lança oficialmente o Programa Nacional de Tecnologia Educacional (Prolnfo) com o objetivo de implementação de laboratórios de informática nas escolas públicas urbanas e rurais. No caso específico do estado de Goiás - Brasil, nesse período, iniciou-se a capacitação profissional, especialmente dos professores, por meio do Curso de Especialização em Informática na Educação, oferecido pelo Prolnfo/MEC em parceria com a Universidade Federal de Goiás (UFG) e o Centro Federal de Educação Tecnológica (CEFET) (BRASIL, 2012).

No ano 2000 a publicação dos Parâmetros Curriculares Nacionais para o Ensino Médio (PCNEM) sinalizaram uma postura diferenciada para com as tecnologias no contexto educacional. Em relação à aprendizagem das Ciências da Natureza, Matemática e suas Tecnologias, os PCNEM (BRASIL, 1999, p. 20) defendem a necessidade de:

"Compreender os princípios científicos presentes nas tecnologias associá-las aos problemas que se propõe solucionar e resolver os problemas de forma contextualizada, aplicando aqueles princípios científicos a situações reais ou simuladas".

Os PCNEM (BRASIL, 1999, p. 80) elucidam ainda a importância de um ensino contextualizado das tecnologias, sendo possível notar essa preocupação a seguir:

"Por sua própria natureza de conhecimento aplicado, as tecnologias, sejam elas das linguagens e comunicação, da informação, do planejamento e gestão, ou as mais tradicionais, nascidas no âmbito das Ciências da Natureza, só podem ser entendidas de forma significativa se contextualizadas no trabalho".

Nas Orientações Educacionais Complementares aos Parâmetros Curriculares Nacionais para o Ensino Médio ( $\mathrm{PCN}+$ ), a estruturação das competências para as Ciências da Natureza e a Matemática apresenta como eixo formativo o entendimento complexo da relação da sociedade com as tecnologias. Em um dos quadros que sinalizam tais competências, é dada significativa 
importância para a análise, a argumentação e o posicionamento crítico diante dos temas da ciência e da tecnologia (BRASIL, 2002).

Para o ano de 2004, um dos eventos mais marcantes no que se refere à relação mídiaeducação foi a IV Cúpula Mundial de Mídias para Crianças e Adolescentes (CMMCA) com o tema "Mídia de Todos, Mídia para Todos". Nesse evento foram escritas as "Cartas do Rio de Janeiro", encaminhadas no mesmo ano ao Conselho Nacional dos Direitos da Criança e do Adolescente (CONANDA) e tinham a defesa do direito das crianças e adolescentes a uma programação de qualidade como objetivo essencial. A 4a CMMCA foi a primeira a promover um fórum com participação exclusiva de jovens num Fórum de Adolescentes que resultou na elaboração de outra carta que expressou o interesse dos jovens em não serem tratados como meros consumidores de tecnologias (CARTAS DO RIO DE JANEIRO, 2004).

Em 2005, acontece em Davos na Suíça o Fórum Econômico Mundial que, dentre outras propostas, apresentou aos países participantes o projeto OLPC (One Laptop Per Child). O governo brasileiro considerou relevante a proposta e logo em seguida montou uma parceria com a FacTI (Fundação de Apoio à Capacitação em Tecnologia da Informação) para avaliar o projeto UCA (Um Computador por Aluno) e adaptá-lo ao contexto nacional. Em 2007 cinco escolas públicas brasileiras foram selecionadas para integrar a fase de testes sobre a efetividade do projeto UCA. Em 2010, a partir do pregão no 107/2008, estabeleceu-se uma parceria com empresas privadas no fornecimento de 150 mil computadores a serem distribuídos para aproximadamente 300 instituições escolares.

Em abril de 2008, o governo federal lança o Programa Banda Larga nas Escolas (PBLE), com o objetivo fundamental de conectar as instituições escolares da rede pública urbana à internet. $O$ governo brasileiro estabeleceu uma parceria com algumas operadoras de serviços de telefonia e de internet para que estas pudessem fornecer suporte técnico à instalação e manutenção da conexão com a internet até o ano de 2025. Anteriormente as empresas de telefonia eram legalmente encarregadas pela instalação de postos de serviços telefônicos (PST) nos municípios e com o novo acordo firmado no Decreto no 6.424, deixam de prestar esse serviço substituindo-o pelos serviços relativos à infraestrutura básica necessária ao PBLE (BRASIL, 2013). A realidade desde então permanece distante dos objetivos acordados a partir de tal parceria supracitada, de modo que ainda existe um número significativo de escolas utilizando uma rede precária de internet salvo os casos em que ela sequer está instalada.

O Projeto de Lei do Plano Nacional da Educação (PL 8035/2010) que estabelece as orientações nacionais para a educação no período de 2011 a 2020 foi aprovado pelo Congresso Nacional e aguarda retorno na Mesa Diretora da Câmara dos Deputados. O Plano Nacional da Educação (PNE) reconhece o papel que a técnica exerce na sociedade atual e de modo mais específico na educação escolar. Um exemplo do comprometimento do PNE em relação à função que as TIC exercem ou podem vir a exercer nas escolas, é notado em uma das estratégias 
elencadas para alcançar a Meta 2 do plano que se refere à universalização do ensino fundamental de nove anos para toda população de seis a quatorze anos (BRASIL, 2011). A estratégia traz:

"Universalizar o acesso à rede mundial de computadores em banda larga de alta velocidade e aumentar a relação computadores/estudante nas escolas da rede pública de educação básica, promovendo a utilização pedagógica das tecnologias da informação e da comunicação".

Em 2011 houve a extinção da SEED e posterior reestruturação no MEC por meio do Decreto № 7.480, de 16 de maio de 2011. Os programas e ações da extinta secretaria passaram a estar vinculados à Secretaria de Educação Continuada, Alfabetização, Diversidade e Inclusão (SECAD). Atualmente, os programas e ações vinculados à SECAD são: Portal Domínio Público, DVD Escola, E-Prolnfo, E-Tec Brasil, PBLE, Proinfantil, Prolnfo, Prolnfo Integrado, TV Escola, Sistema Universidade Aberta do BrasiL (UAB), Banco Internacional de Objetos Educacionais, Portal do Professor, Programa Um Computador por Aluno - Prouca e Projetor Proinfo.

\section{A Raiz Ideológica das Tecnologias}

A acepção ideologia é uma das mais exploradas em investigações científicas e do mesmo modo que alguns outros conceitos amplamente discutidos houve uma apropriação de senso comum em relação à compreensão e uso do termo ideologia. Com isso, nasce uma nova interpretação de caráter fragmentário e com pouca fidedignidade à dimensão conceitual historicamente elaborada. É normal que a sociedade, de forma geral, tenha um entendimento vago sobre a ideologia o que, de certa maneira, possibilita a concretização de mais um dos propósitos da ideologia dominante, a persistência de um número grande de indivíduos apartados do senso crítico. Nesse caso, o provimento insuficiente de componentes formativos para uma consciência coletiva crítica é uma característica normal das sociedades que seguem os princípios de uma ideologia capitalista. Tal característica apesar de se mostrar resistente às investidas transformadoras do conhecimento, não pode ser completamente anulada visto que a própria máquina ideológica não é facilmente substituível ou modificável.

Não há uma raiz ideológica única para todas as tecnologias, deste modo, pode-se entender que para uma determinada técnica é possível trazer à discussão vários aspectos influenciadores de cunho ideológico. Mesmo assim, assume-se que semelhantemente a uma raiz central que emite inúmeras ramificações a ela dependentes, o conjunto de influências que, de uma maneira ou de outra direcionou os caminhos para o desenvolvimento tecnológico contemporâneo, apresenta-se interconectado ao que se denomina aqui como "ideologia de macro influência". Esta é aqui entendida e representada pelo sistema que gera, mantém e estimula a acumulação de capital. 
Partindo da não neutralidade dos fatos e das forças que orientam os caminhos trilhados pelas ciências de forma geral (OLIVEIRA, 2011), propõe-se nessa parte do texto apresentar e discutir os mecanismos pelos quais a ideologia dominante se mantém, incluindo a apropriação de conhecimentos provenientes da técnica no sentido de tornar legítimas as desigualdades sociais e o sistema capitalista. Legitima-se então, a importância do desenvolvimento de um conjunto de argumentações no sentido de amparar uma compreensão mais crítica e complexa da relação entre a ideologia de macro influência e a tecnologia.

A intenção não é criminalizar o papel da tecnologia na transformação social, mas construir um pensamento que depreenda com mais criticicalidade a relação histórica entre ideologia e tecnologia. Portanto, entende-se que a presença das tecnologias no cenário atual é algo inerente ao modelo de sociedade construído e, atrelado a isso, existe um arcabouço ideológico com suas intenções por vezes mascaradas e outras vezes fáceis de serem reconhecidas, porém, difíceis de serem alteradas.

Nesta parte do estudo, a acepção de ideologia se firma fundamentalmente em Thompson (1995) e Chauí (2001). O primeiro autor sustenta a perspectiva da ideologia como o uso de formas simbólicas para instituir ou manter relações de dominação. Para Thompson (1995, p. 15-16), o conceito de ideologia faz referência às maneiras pelas quais "o sentido (significado) serve, em circunstâncias particulares, para estabelecer e sustentar relações de poder que são sistematicamente assimétricas".

Thompson (1995) classifica as formas simbólicas, em contextuais, convencionais, intencionais, estruturais e referenciais. Segundo o autor as formas simbólicas encontram diferentes maneiras de exercer seu poder de influência, podendo ser por manifestações verbais, ações individuais e coletivas, e objetos significativos de vários tipos, sendo estes as variadas formas de interação comunicativa entre os indivíduos na partilha de crenças, experiências e interpretações da realidade.

Para Thompson (1995), existem condições que determinam se uma forma simbólica é ou não ideológica. Diante disso, é preciso saber se elas funcionam ou não na manutenção de relações de dominação. Destarte, para Thompson (1995, p. 90-91),

"As formas simbólicas são ideológicas somente enquanto servem para estabelecer e sustentar relações assimétricas de poder; e é essa atividade, a serviço das pessoas e grupos dominantes, que tanto delimita o fenômeno da ideologia, dando-Ihe especificidade e distinguindo-o da circulação das formas simbólicas em geral, como dá a essa concepção de ideologia proposta um sentido negativo". 
Fundamentando-se no corpo teórico da Teoria Social Crítica com raízes na Escola de Frankfurt, Thompson (1995) propõe a teoria da mídia em sua obra intitulada Ideologia e Cultura Moderna. Nesse trabalho, é colocada em discussão a "Teoria Social Crítica na era dos meios de comunicação de massa". A obra apresenta ainda a "Hermenêutica da Profundidade" (HP), um novo caminho metodológico para um processo interpretativo complexo no estudo do contexto sócio-histórico do fenômeno social. A partir da interpretação de Veronese \& Guareschi (2006), a HP pode ser brevemente descrita como um referencial teórico metodológico que busca analisar a ideologia como um campo social importante, atribuindo um caráter potencialmente crítico à pesquisa. Thompson (1995) considera a interpretação da ideologia como uma manifestação específica da HP no sentido de compreender as relações de sustentação ideológica a partir de determinadas formas simbólicas.

A segunda proposta de entendimento do conceito ideologia é proposto por Chauí (2001) cuja compreensão de ideologia demonstra caminhar junto com as interpretações de Thompson (1995) ao discutir a estratificação social criada e mantida pelo poder ideológico. Ambos os autores são marxistas e entendem a ideologia como uma forma de ocultamento da realidade social injusta e fundada a partir das relações de exploração da força de trabalho. Chauí (2001, p. 108-109) propõe o entendimento da ideologia da seguinte forma:

"A ideologia é um conjunto lógico, sistemático e coerente de representações (ideias e valores) e de formas ou regras (de conduta) que indicam e prescrevem aos membros da sociedade o que devem pensar e como devem pensar, o que devem valorizar e como devem valorizar [...]. Ela é, portanto, um corpo explicativo (representações) e prático (normas, regras, preceitos) de caráter prescritivo, normativo regulador, cuja função é dar aos membros de uma sociedade dividida em classes uma explicação racional para as diferenças sociais, políticas e culturais, sem jamais atribuir tais diferenças à divisão da sociedade em classes a partir das divisões na esfera da produção".

De maneira articuladamente complexa, está o que Chauí (2001) chama de ideologia da competência. Esta exerce seu poder de dominação pelo status de superioridade atribuído ao conhecimento científico e tecnológico. Ou seja, a especialização em uma das inúmeras áreas consideradas elaboradoras de novas técnicas, confere ao indivíduo ou mesmo a uma instituição, uma posição elevada no contexto social. Emerge então, uma divisão social entre os "competentes (especialistas que possuem conhecimentos científicos e tecnológicos) e os incompetentes (os que executam as tarefas comandadas pelos especialistas)" (CHAUÍ, 2001, p. 105).

Torna-se relevante descrever, ainda que brevemente, um compêndio de alguns dos principais eventos históricos que deram condições para a criação de um sustentáculo mediante o qual, a ideologia de macro influência pudesse se firmar e se desenvolver. É importante destacar que tais eventos históricos sustentam entre si uma relação de interdependência. 
O primeiro compilado de eventos históricos refere-se ao nascimento do capitalismo industrial no continente europeu, seguido pelo enfraquecimento de algumas crenças e práticas religiosas preponderantes em sociedades cujo crescimento industrial ainda se encontrava em estágios iniciais. Com a influência e a abrangência do capitalismo industrial crescendo progressivamente, algumas mudanças relevantes no cenário sociocultural também cresceram pronunciadamente, deixando a estruturação social cada vez mais baseada nos saberes do campo científico.

De maneira amplamente relacionada ao contexto supracitado, localiza-se a associação entre os reflexos socioeconômicos da Revolução Industrial ocorrida em meados do século XVIII na Inglaterra, da Revolução Demográfica da Europa de 1789 e do lluminismo cujo apogeu foi atingido no século XVIII. Esses reflexos marcaram a queda da hegemonia religiosa sobre as decisões e interesses sociais e fortaleceram o discurso da razão (HUBERMAN, 1984). A partir de então, os direcionamentos da sociedade passaram a atribuir às construções teóricas das ciências e suas tecnologias como principal fonte de orientação.

Sob o ponto de vista da cultura e suas relações com a tecnologia, alcançar ou não uma noção crítica das tecnologias se reflete em duas situações antagônicas. Por um lado, o uso crítico dos atributos tecnológicos faz com que culturas distintas deliberadamente se apropriem da técnica no sentido de manter e divulgar sua identidade única, respectivamente dentro e fora dos seus domínios. Por outro lado, as tecnologias, com destaque às TIC, ao encontrarem um terreno inabitado pela cognição crítica, acabam por massificar os aspectos culturais, tornando-os comuns, mesmo em sociedades diferentes.

A cultura pode ser concebida, de acordo com Geertz (1978), como um conjunto de sistemas simbólicos nos quais sentidos e significados são transmitidos e compartilhados pelos indivíduos de um grupo social. Geertz (1978, p. 15) diz ainda que "o homem está amarrado a teias de significado construídas por ele, sendo a cultura, essas teias".

Pode-se estabelecer um diálogo entre Geertz (1978) e Thompson (1995), quando este afirma que os sistemas simbólicos são produzidos, transmitidos e recebidos embebidos sóciohistoricamente em relações de poder e de conflitos. Destarte, a técnica além de ser um enlaçamento de fios que compõem teia da cultura científica, possibilita antagonicamente condições de valorização e rompimento de fronteiras bem como de extinção de manifestações culturais.

Um dos exemplos mais notáveis de tal produção, transmissão e recebimento de sistemas simbólicos no cenário socioeconômico brasileiro aconteceu no período da ditadura militar de 1964. Na época, grande parte do poder era mantido pela apropriação das tecnologias de comunicação em massa. A eficácia de tal apropriação foi conseguida em grande parte graças à televisão promovendo assim, a chamada "integração nacional" da cultura e da ideologia. O 
elemento central na função de porta voz dos interesses do golpe militar foi a Rede Globo de Comunicação que realçava problemas externos ao Brasil, mascarava e distorcia os conflitos internos alimentando os mecanismos de repressão intentando legitimá-los (BÉVORT e BELLONI, 2009).

Mas quais direcionamentos devem ser seguidos para alcançar uma dissolução dos poderes ideológicos? O primeiro passo é compreender que não se vive numa completa ausência de fatores ideológicos e que tal dissolução implica em desenvolver uma crítica da ideologia (CHAUÍ, 2001) ou semelhantemente nas palavras de Thompson (1995), alcançar uma ideologia crítica. Nessa direção, Chauí (2001, p. 118) lança mão de um questionamento relevante que diz o seguinte:

"Quem e o que pode desmantelar a ideologia? Somente uma prática política nascida dos explorados e dominados e dirigida por eles próprios. Para essa prática política é de grande importância o que chamamos de crítica da ideologia, que consiste em preencher as lacunas e os silêncios do pensamento $e$ discurso ideológico, obrigando-os a dizer tudo que não está dito, pois dessa maneira a lógica da ideologia se desfaz e se desmancha, deixando ver o que estava escondido e assegurava a exploração econômica, a desigualdade social, a dominação política e a exclusão cultural".

A partir do exposto, infere-se que a ideologia de macro influência capitalista se apodera dos benefícios conseguidos pelo desenvolvimento tecnológico transformando-os em novos instrumentos de persuasão e de incentivo à legitimação do modus operandi do sistema de dominação. Portanto, torna-se imprescindível investir na formação crítica do indivíduo tendo em vista que a ideologia é, antes de qualquer coisa, uma construção e uma interpretação humana passível de mudanças em sua estrutura.

\section{Considerações Finais}

A presença e a importância dos elementos da técnica na sociedade atual são inegáveis. 0 que se nega historicamente é o conjunto de condições formativas que permitem a incorporação efetiva das tecnologias nas escolas sob uma perspectiva crítica. A distância entre o mundo dos jovens das gerações mais novas e o mundo escolar é reconhecidamente grande, mas faz-se pouco para atenuá-la e quase nada para extingui-la.

A técnica exibe dicotomicamente duas conjunturas no que se refere à temática mídiaeducação: por um lado tem-se o crescente entendimento do potencial pedagógico associado às TIC e, por outro, a preocupação velada de um sistema econômico em proporcionar condições de permanência e legitimação dos seus propósitos. Mas não se tratam simplesmente de conjunturas dicotômicas de igual peso ou relevância. A segunda exerce uma forte influência sobre a primeira 
deixando-a crescer e se desenvolver sob a imposição de alguns limites para que não se torne forte o suficiente ao ponto de abalar a estrutura essencial do capitalismo.

O que está verdadeiramente em jogo não é a promoção da qualidade do ensino assistida pelos variados tipos de tecnologias e sim a incorporação maciça da técnica no ambiente escolar para que este continue sendo um espaço de reprodução de ideias, poderes, sistemas simbólicos e interesses ideológicos. Nesse caso, a ideologia de macro influência capitalista há muito tempo notou que não se pode obter um processo "formativo" coerente com as necessidades emergentes deste tempo, sem introduzir largamente a tecnologia em todos os espaços, sobretudo o escolar. Culturas que não obedecem aos padrões ocidentais de consumo tecnológico são erroneamente consideradas mais simples e "merecedoras" de mais tecnologia no cotidiano das pessoas.

Concebendo analogicamente a realidade como uma árvore, com relação às TIC na educação, pode-se dizer que as raízes historicamente localizadas foram absorvendo nutrientes da ideologia vigente e dando origem a um tronco único, que pode ser entendido como a relação humana para com a tecnologia em geral. Em seguida, tal relação já dependente dos pressupostos e regras ideológicas, se subdivide complexamente em inúmeros ramos. Estes representam os múltiplos contextos da vida numa sociedade marcadamente tecnológica e que continuam a produzir novos ramos incluindo o ramo nomeado de educação escolar brasileira. Ao elevar o pensamento ao nível da criticicalidade, criam-se condições de florescimento de uma nova realidade educacional, mais justa e coerente com seus objetivos.

\section{Referências}

ALMEIDA, M. E. B. Tecnologias na Educação: dos caminhos trilhados aos atuais desafios. Bolema: Rio Claro, Ano 21, n. 29, p. 99-129, 2008.

ALTOÉ, A.; SILVA, H. da. O Desenvolvimento Histórico das Novas Tecnologias e seu Emprego na Educação. In: ALTOÉ, Anair; COSTA, Maria Luiza Furlan; TERUYA, Teresa Kazuko. Educação e Novas Tecnologias. Maringá: Eduem, 2005, p. 13-25.

BAUER, T. A. O valor público da Mídia Literacy. Líbero, São Paulo, v. 14, n. 27, p. 9-22, 2011. BÉVORT, E.; BELLONI, M. L. Mídia-Educação: conceitos, história e perspectivas. Educação \& Sociedade, Campinas (SP), v. 30, n. 109, p. 1081-1102, 2009.

BRASIL. Ministério da Educação e Cultura. LDB - Lei no 4024 de 20 de dezembro de 1961. Fixa as Diretrizes e Bases da Educação Nacional. Brasília: MEC, 1961. . Ministério da Educação e Cultura. LDB - Lei no 5.692 de 11 de agosto de 1971. 
. Ministério de Educação. LDB - Lei no 9.394 de 20 de dezembro de 1996. Estabelece as diretrizes e bases da Educação Nacional. Brasília: MEC, 1996. Ministério da Educação, Secretaria da Educação Média e Tecnológica. Parâmetros Curriculares Nacionais para o Ensino Médio. Brasília: MEC, SEMTEC, 1999. . Ministério da Educação, Secretaria da Educação Média e Tecnológica. PCN+ Ensino Médio: orientações complementares aos Parâmetros Curriculares Nacionais. Ciências da Natureza, Matemática e suas Tecnologias. Brasília: MEC, SEMTEC, 2002.

. PL no 8.035 / 2010 / organização: Márcia Abreu e Marcos Cordiolli. Brasília, Câmara dos Deputados, Edições Câmara, 2011. . Ministério da Educação, Secretaria de Educação a Distância. Programa Nacional de Informática na Educação. 2012. Disponível em:

<http://sip.proinfo.mec.gov.br/relatórios/indicadores_rel.html\#Doze>. Acesso em: 04 de maio de 2013.

. Ministério da Educação. Secretaria de Educação a Distância. Programa Banda Larga nas Escolas. 2013. Disponível em:

$<$ http://portal.mec.gov.br/index.php?option=com_content\&id=15808>. Acesso em: 28 de abril de 2013.

BUARQUE, C. La cortina de oro: los sustos técnicos y sociales de fin de siglo y un sueño para el próximo, Brasilia: Comunica, 1997. (Coleção utopos).

CASTELLS, M. A sociedade em rede: do conhecimento à ação política. Santa Cruz (RJ): Casa da Moeda, 2005. 435p.

CHAUÍ, M. O que é ideologia. São Paulo: Brasiliense, 2001. 119p (Coleção Primeiros Passos; 13).

DALE, R. Globalização E Educação: demonstrando a existência de uma "cultura educacional mundial comum" ou localizando uma "agenda globalmente estruturada para a educação?". Educação \& Sociedade, Campinas (SP), v. 25, n. 87, p. 423-460, maio/ago. 2004.

DIEUZEIDE, H. Mass media, éducation et culture. Perspectives. Revue Trimestrielle de l'Éducation, Paris, v. 10, n. 1, p. 43-47, 1980.

DOMINGUES, C. de O. "Technologie et crise" (une approche systemique), Thése pour le doctorat d'état, Universite de Paris X-Nanterre, Paris, 1986.

DONNAMARIA, C. P.; e TERZIS, A. Algumas notas sobre as relações humanas mediadas por computadores. Mental [online]. 2012, v. 10, n. 18, p. 165-178.

DUART, J. M.; SANGRÀ, A. Aprender en la virtualidad. Barcelona: Gedisa, 2000.

GAMA, R. A Tecnologia e o Trabalho na História. São Paulo: Nobel Edusp , 1987. 
GEERTZ, C. A interpretação das culturas. Rio de Janeiro: Zahar, 1978.

GOIÁS. Secretaria de Estado da Educação. Portaria № 4060/2011-GAB/SEE. 2011.

HUBERMAN, L. História da riqueza do homem. Tradução Waltensir Dutra. 20ạ. ed. Rio de Janeiro: Zahar, 1984.

KENSKI, V. M. Tecnologias e ensino presencial e a distancia. Campinas (SP): Papirus, 2003.

KENSKI, V.M. A profissão do professor em um mundo em rede: exigências de hoje, tendências e construção do amanhã: professores, o futuro é hoje. Tecnologia Educacional, v. 26 (143), p. 6569, 1998.

KNELLER, G. F. A Ciência como Atividade Humana. São Paulo. ZAHAR/EDUSP, 1978.

LÉVY, P. Cibercultura. Tradução de Carlos Irineu da Costa. São Paulo: Ed. 34, 1999. 264p.

. As tecnologias da inteligência. São Paulo: Ed. 34, 1993.

MARCONDES FILHO, C. Televisão. São Paulo: Scipione, 1994.

NOGUEIRA, A. G. E a coruja voou para a Internet. REAd, v. 4, n. 1, p. 1-16, 1998.

OLIVEIRA, M. Formas de autonomia da ciência. Scientiae Studia, São Paulo, v. 9, n. 3, p. 527-61, 2011.

ORGANISATION DES NATIONS UNIES POUR L'EDUCATION, LA SCIENCE ET LA CULTURE (UNESCO). L'education aux médias. Paris, 1984.

PERRENOUD, P. Les Pratiques pédagogiques changent-elles et dans quel sens? Pour: Revue de la Fédération Syndicale Unitaire. Paris, n. 65, p. 14, maio de 2000.

PORTUGAL. Ministério da Educação. Equipe Computadores, Redes e Internet na Escola. Programa de tecnologias da informação e comunicação: 9 e 10 anos. Autoria de Sónia Mildred João. Lisboa, 2003. Disponível em: <http://www.dgidc.minedu.pt/programs/prog_hom/recorrente/tic_10.pdf> Acesso em: outubro de 2012.

PRETTO, N. Uma escola sem/com futuro: educação e multimídia. Campinas: Papirus. 1996. 247p. RIO DE JANEIRO. Cartas do Rio de Janeiro. In: 4ạ Cúpula Mundial de Mídia para Crianças e Adolescentes. 2004. Disponível em:

<http://www.mp.rs.gov.br/areas/infancia/arquivos/carta_do_rio.pdf. > Acesso em 28 de abril de 2013.

THOMPSON, J. B. Ideologia e cultura moderna: teoria social crítica na era dos meios de comunicação de massa. Petrópolis, Rio de Janeiro: Vozes, 1995. 
UNICAMP. Projeto Educação com Computador. Disponível em:

http://pan.nied.unicamp.br/publicacoes/publicacao_detalhes.php?id=98. Acesso em: 20 de abril de 2013.

VALENTE, J.A; ALMEIDA, F.J. Visão Analítica da Informática no Brasil: a questão da formação do professor. In: Revista Brasileira de Informática na Educação: SBIE, n. 1. 1997.

VERONESE, M. V.; GUARESCHI, P. A. Hermenêutica da profundidade na pesquisa social. Ciências Sociais Unisinos, n. 42, v. 2, p. 85-93, maio/agosto de 2006.

WOOD, Ellen Maiksins. Democracia contra Capitalismo. A renovação do materialismo histórico. São Paulo: Boitempo, 2003.

Jefferson Fagundes Ataíde: Programa de Mestrado em Educação em Ciências e Matemática da Universidade Federal de Goiás. E-mail: ataíde.jefferson@gmail.com.

Nyuara Araújo da Silva Mesquita: Instituto de Química da Universidade Federal de Goiás. E-mail: nyuara@ufg.br. 